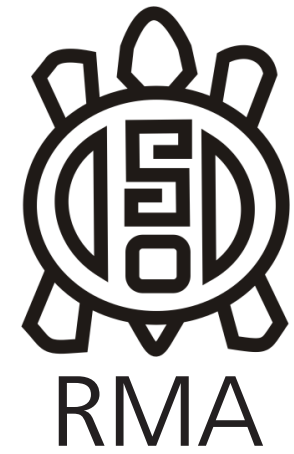

Dossier

\title{
O riso e o risco da prosa: uma comparação entre o bocage francês e o sertão rosiano brasileiro
}

\author{
The prose's laught and risk: a comparison between the french \\ bocage and the brazilian sertão
}

Ana Carneiro

Centro de Formação em Ciências Humanas e Sociais da Universidade Federal do Sul da Bahia (CFCHS/UFSB). E-mail: anacarcer@gmail.com

\begin{abstract}
Resumo
A partir da etnografia dos Buracos, povoado de pequenos agricultores no Sertão norte-mineiro, Brasil, lanço foco sobre momentos de "cisma" nos quais determinadas relações pessoais colocam-se em risco devido a conversas truncadas. Este risco é objeto de preocupação constante dos buraqueiros, que em geral se autoproclamam pessoas de "boa prosa" e "consideração"; contrárias às "cismas". Esta preocupação atenta aos riscos da prosa guarda alguns pontos de comparação com as atitudes de receio e cautela que os agricultores do Bocage francês desenvolvem diante do "sistema de feitiçaria" etnografado por Jeanne Favret-Saada. Tal etnografia serve aqui para, no contraste, explicitar como, nos Buracos, o risco da prosa não é uma ameaça à vida social, mas ao contrário, é-lhe constitutivo, quiçá desejado e buscado através do humor.
\end{abstract}

Palavras-chave: Conversa; Humor; Sertão norte-mineiro; Fofoca; Corpo.

\begin{abstract}
The people of Buracos, populated by small farmers at Minas Gerais state, interior of Brazil, is described here focusing on moments of "schism" and "suspiction" in which certain personal relationships are at risk due to garbled conversations. This risk is a constant concern object of buraqueiros, which usually call themselves people of "good prose" and "consideration"; contrary to "schisms". This concern attentive to the risks of prose keeps some points of comparison with the attitudes of fear and caution that farmers of French Bocage develop before the "witchcraft system" ethnographed by Jeanne Favret-Saada. This ethnography, in contrast, helps to explain how, in Buracos, the prose's risk is not a threat to social life, but on the contrary is desired and pursued through humor.
\end{abstract}

Keywords: Talk; Humor; Sertão of Brazil; Gossip; Body.

\section{A prosa e o corpo}

Com pouco mais de 40 casas onde vivem famílias de pequenos agricultores, o povo dos Buracos situa-se no interior de um cânion, 30 metros abaixo do "gerais", planalto antes coberto pelo cerrado, recentemente rareado pelas monocultoras de soja e capim, ao norte do estado de Minas Gerais, interior do Brasil. A região é amplamente reconhecida como cenário do Grande Sertão: veredas, romance de J. Guimarães Rosa que explora um traço importante para nossa análise: o valor e o esmero que a população local destina à arte da conversa, ou da "prosa", para usar um termo nativo. "Contar causo" é a atividade de lazer primordial naquela localidade; corriqueira e prazerosa, indicadora de boas relações e conhecimento. Um "causo" pode-se definir como um conjunto de versões contadas sobre um determinado ocorrido, estabelecendo uma cadeia narrativa formada por um circuito de pessoas que se comunicam, isto é, um certo "povo" 1.

Ao contar um causo controverso, o narrador costuma botar em evidência as diferenças notadas entre versões ouvidas, e desvela assim a instabilidade das relações pessoais que formaram tal cadeia narrativa. Neste artigo, lançarei foco sobre tais momentos de "cisma", nos quais determinadas relações pessoais parecem estar em risco devido a conversas truncadas. Este risco - o da prosa "descombinar" - é um objeto de preocupação constante dos buraqueiros, que em geral se autoproclamam pessoas de "boa prosa" e "consideração", isto é, contrárias às "cismas".

Como pretendo mostrar mais adiante, esta preocupação atenta aos riscos da prosa guarda alguns pontos de comparação com as atitudes de receio e cautela que os agricultores do Bocage francês desenvolvem diante do

\footnotetext{
${ }^{1}$ Este artigo reproduz a ideia central e alguns trechos do capítulo final de $O$ povo parente dos Buracos (Carneiro, 2015-b).
} 
"sistema de feitiçaria" etnografado por Jeanne FavretSaada (2005 [1977]). Tal etnografia servirá aqui para, no contraste, explicitar uma singularidade dos Buracos, onde o risco não parece ser uma ameaça à vida social, mas ao contrário, é-lhe constitutivo, quiçá buscado e desejado pelas pessoas que ora o evitavam. Existem, entretanto, maneiras condicionantes de se desejar o desequilíbrio da prosa; a ameaça de ruptura deve desembocar em risada, não em conflito.

Nos causos de briga, os efeitos negativos de certos encontros são como "misturas que não dão bem". É como quando se come uma "comida forte" e o "corpo está fraco" - "não dá bem"; "é mode o sistema que não combina", "a prosa não bate". Mas no caso da prosa, por que duas pessoas descombinam?, pergunto. "É mode o que sistema que descontrola, é mode o sangue mesmo da pessoa, da prosa ruim de alguém", respondemme. Qualquer um está sujeito à "prosa ruim", isto é, à "falação", ao "disse-me-disse", à "fofoca", à "desfeita", entre outras. Todas estas modalidades de "conversa" são, como ouvi certa vez, "parentes do feitiço". Há quem diga que não, que "feitiço é outra coisa", contudo, sendo ou não da mesma natureza, a prosa ruim é facilmente observada como uma variação do feitiço - uma variação mais corriqueira e menos nefasta (pois não leva à morte) da arte de se provocar, pela palavra, o desequilíbrio das relações pessoais e da saúde física e psíquica da pessoa "mal falada" ou "contrariada"2. Muito comum, por exemplo, é que a prosa ruim de um marido, durante o período de "resguardo" da mulher recém-parida, cause nesta uma enfermidade crônica, como dores de cabeça constantes ao longo da vida. Um outro causo é o da mulher que emagrece quando, após se casar, vai morar perto da família do marido e não "combina" com os afins, tornando-se mal-falada.

Causos como estes serão, por suas vez, tema de outras formas de prosas arriscadas, as chamadas "fofocas". Nestas, o processo significativo da conversa coloca em primeiro plano as transformações relacionais e corpóreas produzidas pela transmissão da informação. O conteúdo da fofoca só tem importância à medida que revela e significa as posições relacionadas por certo ato de comunicação. Quem é falado? Quem acusa? Em suma, quem fala o que de quem e para quem? Estas são as questões de interesse em uma rede de fofoca ${ }^{3}$. Quando se narram os causos da esposa mal-falada ou da quebra de resguardo por prosa ruim do marido, é sobre relações pessoais e transformações do corpo que se trata; é muitas vezes pela alteração no corpo que se diagnostica o quanto uma pessoa foi afetada pela prosa de outrem.

\section{Corpo coletivo}

2 Emprego aqui o termo "arte" entendido como "modo de fazer", a exemplo da ideia de "artesanato", no caminho já trilhado por De Certeau (1990)

${ }^{3}$ Sobre a relação entre a fofoca e as práticas cotidianas da "pequena política", como sugiro aqui, vale conferir, entre outros, Besnier (2009), Darnton (2010) e Jackson (2008).
"O sistema às vezes descontrola", dizem-me eles. É quando a mistura "não dá bem", quando a prosa "não bate", é uma espécie de mal encontro. O mal encontro, na elaboração deleuziana da filosofia de Spinosa, é uma mistura de corpos que tem por efeito enfraquecer a potência de ação (puissance d'agir) (Deleuze, 1978). Nos "causos" dos Buracos, os atos de fala que malditas (ou mal-ditas), diagnosticadas nos efeitos dos corpos (sangue), repercutem a formulação sobre o encontro e a maldade, que Deleuze explora a partir da ideia de afeto. Entendido por Deleuze como pensamento nãorepresentativo, o conceito sipinosista de afeto (affectus) é determinado como sendo a variação de nossa potência de ação. Ele diferencia assim afeto (affectus) de afecção (affeccion), definido como o estado de um corpo, quando submetido à ação de outro corpo; como mistura de corpos, que os transforma (idem).

Mas o que seria um "corpo" para Deleuze? Em uma reflexão sobre o tema, o autor abrevia Spinosa: a individualidade de um corpo define-se pelo que permanece na relação complexa (composta ao infinito) entre movimentos e repousos. Há portanto uma dimensão temporal importante, de alguma forma similar ao que observei sobre o povo dos Buracos. Ali, o modelo nativo de coletividade pode ser visualizado à medida que observamos o "sistema" de uma "mexida de cozinha", sobretudo porque ali se compõe cotidianamente um conjunto virtualmente ilimitado de conversas que, ao circular, são variáveis e variantes, mantendo porém a unidade do conjunto ${ }^{4}$. Temos então, em cada conversa, um agenciamento coletivo singular, e o que se coloca é o problema da estabilidade desta forma coletiva. Isto é indicado precisamente na expressão "povo", cujo enunciado evoca simultaneamente um e vários "povos": o povo de Fulana, por exemplo, é o de seus "chegados", o de sua "casa", o de sua "família", o de sua "comunidade" (a "comunidade" ou "povo" dos Buracos). "Povo" pode ser mesmo a referência a uma única "pessoa", entrevista sozinha em local onde não se sabe se havia ou não outros "dos dela". Assim, a forma como um mesmo causo varia à medida que circula também nos faz ver esta relação entre a singularidade do conjunto atrelada às singularidades pessoais, sem que isto possa significar dois planos distintos de individualidade (ou "povo" e a "pessoa"). Em suma, o "povo" dos Buracos compõe-se de um conjunto ilimitado de "povos" e "pessoas", uns mais outros menos estáveis (os povos formados na cozinha, por exemplo, duram no máximo algumas horas). E se o hábito de "contar causos" efetua, ao circular, a criação constante

\footnotetext{
${ }^{4}$ Um grupo de pesquisadores do qual faço vem debatendo etnografias sobre movimentos humanos que não aparecem como unidirecionais ou dispersivos, mas sim constitutivos de processos de coletivização específicos (cf. Andriolli, 2011; Benites, 2010; Comerford,1999 e 2003; Dainese, 2011; Guedes, 2013; Medeiros, 2011; Pereira 2004 e 2011; e Weitzman, 2011). A discussão segue na esteira de uma antiga reflexão sobre a categoria migração, levada a cabo por Palmeira e Almeida (1977). Para uma abordagem desta discussão recente a partir da questão da circulação de prosa e comida, ver Comerford, Carneiro e Dainese (2015) e Carneiro (2009; 2013; 2014; 2015). Para uma perspectiva comparativa etnográfica, ver Carneiro e Dainese (2015).
} 
de um "povo", ele não é pessoal apenas no sentido de criar uma coletividade, mas também da dimensão íntima, subjetivada, "pessoal", que esta engaja. Se de um lado, o "sistema" forma "um pessoal", isto é "um povo", nos arranjos reunidos pela troca de prosa e comida; de outro (e concomitantemente), este povo mobiliza necessariamente processos de subjetivação criados nos posicionamentos de cada um dos falantes que, por sua vez, só existem na singularidade do conjunto.

Se o povo pode ser uma ou muitas pessoas, se pode ser sinônimo de família, gente, comunidade, amigos, vizinhos e mesmo apenas pessoas, sem fazer distinção entre o hum e o múltiplo, e se além disto - veremos - ele não é determinado inteiramente pela "terra" em que habita, é porque há, na formação coletiva chamada "povo", uma dimensão importante de intensividade, o que me permitiu pensá-lo como multiplicidade, conforme a elaboração de Gilles Deleuze e Félix Guattari (cf. por exemplo Deleuze, 2006 [1968]; 2000[1969]; Deleuze e Guattari, 1980). O "sistema do povo", sua circulação de prosa e comida, faz-se do encadeamento - ou encontro - de conversas contingentes, ela é precisamente uma singularidade, no sentido que estes autores associaram à ideia de multiplicidade. Como ressaltou François Zourrabichvilli (2004: 73-74), os dois conceitos mostramse necessariamente solidários; a singularidade é sempre relativa a uma multiplicidade, é uma organização própria do múltiplo. A singularidade é pré-individual, nunca isolável, prolonga-se até a vizinhança de uma outra, só existe como agenciamento heterogêneo.

Por este caminho, Deleuze confronta-se com um problema que nós antropólogos costumamos ver como paradoxo insolúvel, o da alternativa entre as agências do indivíduo e da sociedade. É importante para meu intuito que este caminho teórico esteja vinculado a uma crítica da representação; instigando-nos a uma outra ideia de produção de sentido ao mesmo tempo em que nos livra do drama da representatividade dos grupos que estudamos, isto é, relacionando as problemáticas dos "causos" e dos "povos". Para a representação, as singularidades seriam predicados atribuíveis a sujeitos, isto é, atributos exclusivos, o que implica uma identidade imutável, isolada, autônoma. Deleuze argumenta que, diversamente, o sentido não tem a ver com predicação. As significações não são anteriores ao sentido, não são elas que lhes dão origem, assim como as singularidades não são anteriores ao agenciamento heterogêneo que Ihes dá existência.

\section{Povo e pessoa: sistemas}

O povo é "dos Buracos", mas encontra-se não só nos Buracos como também em Brasília, São Paulo, Chapada Gaúcha... "Até no povo do Ribeirão tem gente nossa, do povo dos Buracos". Se não é o espaço geográfico que os define, o povo tampouco se reduz aos laços sanguíneos.
"Aqui todo mundo toca parentesa, mas também mistura muito, casa com gente de fora, de outras famílias. Vai tocar parentesa muito longe, e tem gente fora que é mais parente". Quem é então esse "nós" do povo dos Buracos? Que unidade conceitual é esta?

A maneira como costumam se referir ali ao "sistema da pessoa" ou "sistema do povo" apareceu como pista interessante diante desta questão. O que é sistema?, comecei a perguntar. "Ah... é o modo de comer, o modo de conversar", respondiam-me automaticamente, sempre nesta ordem. "Cada povo tem seu sistema". E em seguida: "O povo gaúcho tem um sistema esquisito. Gaúcho não é gente!". Sobre os gaúchos, dizem também que têm "um de-comer esquisito!", "uma prosa enjoada", "não comem de junto da gente", "não chamam pra tomar um café, é da porta pra fora". "Mas tem gaúcho que parece até gente nossa, vive no mesmo sistema nosso, aí já virou mineiro". O que define o povo seria então "o sistema". Nenhum mistério, o análogo perfeito ao que nós cientistas humanos entendemos como sistema social. Só que não.

À medida que se trata de prosa e comida, é nas movimentações diárias que as relações do sistema se exprimem - deslocamentos em função da lenha para o fogão, lida na roça, ou um dedo de prosa na casa cunhada vizinha. As movimentações também são intensivas - por exemplo o modo da dona da casa, se tem a prosa mansa ou agitada, se é animada ou fraquinha. Também entre as casas existem movimentações mais ou menos intensas, varia conforme a vizinhança, mas também conforme o casamento ou a amizade. Se a prosa combina, o sistema dá bem, o povo vai na casa uns aos outros mesmo que as casas sejam distantes.

Cada casa é dinamizada de acordo com os "modos" pelos quais a comida "puxa" a "prosa", que por sua vez puxa mais "comida" - e assim seguem. Esse é o sistema da casa. Esta circulação de prosa e comida não só indica como também cria a "intimidade", o "costume", o bem querer" - é quando a prosa dá bem, o sistema combina. Isto acontece quando o povo gosta da comida uns aos outros, porque é assim que o povo repete a pratada e puxa mais prosa; gostando da prosa, puxa mais comida.

Mas nem sempre o sistema de uns aos outros combina. Não raro o sistema "descontrola", é o desentendimento de uma conversa atravessada ou um disse-me-disse dos outros. O confronto entre versões narradas de um determinado causo. Quando as narrativas são postas em contraste e alguém encontra incongruência, é quando começa a fofoca. E aí já sabe, a fofoca é prima da inveja, que é irmã do feitiço. É quando o "sistema descontrola". O causo e suas versões conflitantes podem portanto nos ensinar sobre o sistema do povo. A variação das versões de um mesmo causo não correspondem necessariamente à distância geográfica maior ou menor entre as casas onde os causos são narrados. A versão varia antes em 
função do circuito de relações pessoais, isto é, de visitas, de circulação de prosa e comida. Analisar um causo é analisar as relações que o informam, sobre isso falam suas variações.

\section{Buracos e Bocage}

Jeanne Favret-Saada também falou de afetos e corpos. Após longa pesquisa de campo, nos anos 70, na região do Bocage - nome para uma vaga localização no interior da França -, a autora começou a reconsiderar a ideia de afeto como noção central para a pesquisa etnográfica (cf. Favret-Saada, 2005 [1990]: 155), e é então que o discurso da feitiçaria aparece em sua síntese: ocupar o lugar do outro, afetando-se pelos mesmos atos que os afetam, é ocupar um lugar no sistema de lugares da feitiçaria. Isto, escreve ela, "não me informa nada sobre o afeto do outro", mas "mobiliza ou modifica meu próprio estoque de imagens" (Favret-Saada, 2005 [1990]: 159). Nisto reside um gênero de conhecimento específico do povo do Bocage sobre "os outros" deles; um saber que - por este caminho - pode ser simetrizado ao conhecimento etnográfico ${ }^{5}$.

Similarmente ao que observei nos Buracos, a autora mostra a variação de uma intensidade vital e pessoal em função de um certo regime discursivo - que ela identifica, no Bocage, como discurso da feitiçaria ou sistema da feitiçaria. Em ambos os contextos etnográficos, o ato verbal pode ser - mais do que desestabilizador extremamente violento, efetuando uma sequência de males inexplicáveis, em geral ligados aos corpos da vítima e de seus animais de criação. Há uma clara proximidade entre os dois "sistemas", o do povo dos Buracos e o da feitiçaria no Bocage. Ambos colocam em continuidade corpos e discursos, ou "modos de comer e de conversar", como diriam os buraqueiros.

Por esta abordagem, em Les mots, la mort, les sorts, Favret-Saada argumenta sobre o Bocage que os enunciados ligados à feitiçaria não podem absolutamente ser entendidos como representação, ou (pior) como crença, que seria a representação de uma ideia falsa. Seu tratamento sobre o sistema da feitiçaria voltase então para os atos de enunciação. Estes atos são processos significativos e transformadores, alteram o estado das pessoas e de suas relações. Há em relação a tais atos uma série de comportamentos codificados, em que a comunicação evita a todo custo a verbalização. No Bocage, a autora presenciou por exemplo um "riso demonstrativo" (Favret-Saada, 2005 [1977]: 274-282): em uma situação de combate entre enfeitiçado e feiticeiro, o

\footnotetext{
${ }^{5}$ A relação entre etnografia e feitiçaria recebe uma bela elaboração feita por Barbosa (2012), que em sua análise sobre o trabalho de FavretSaada aproxima a autora da ideia de simetrizção, conforme Goldman e Viveiros de Castro, 2006). Por um caminho similar ao feito aqui, Barbosa mostra que a consistência conceitual singular da feitiçaria permite implicações teóricas importantes a uma "antropologia da feitiçaria".
}

primeiro fez os presentes rirem do susto que o feiticeiro levou. Assim, sem qualquer palavra, todos se colocaram em acordo sobre o que ninguém seria capaz de dizer: houve feitiço e ali estava o culpado, o feiticeiro, assustado e enfraquecido pelas risadas. O riso fora uma forma sábia de comunicar sem assumir o lugar de acusador, o que colocaria o falante na posição de annonciateur, envolvendo-o no sistema de lugares da feitiçaria. O riso significou, naquela situação, o fim da ambiguidade, demonstrando o que todos já sabiam, ou desconfiavam, mas que haveriam de manter na zona sombria do silencio, sem a coragem de dizer.

Esta espécie de causo contado por Favret-Saada leva-nos a um interessante ponto de distanciamento em relação ao que observei nos Buracos, que descreverei aqui a partir de um outro causo...

Foi quando Julia, uma jovem e bela buraqueira, questionava-se sobre os rumos de seu casamento. O fato de viver "em pé de guerra" com o marido era formulado por ela nos termos de um "destino" que poderia ser atribuído a dois fatores opostos, a "escolha" ou a "sorte". Os dois termos na verdade escondiam um terceiro. Ao refutar o sinal da "sorte", poderia estar se referindo a dois sentidos distintos, ambos inescapáveis; um dado por Deus, outro feito por gente. Perguntava-me portanto se a sorte à qual se negava seria o "destino dado por Deus", sentido explicitável, ou a alguma "coisa feita por gente". Não há como saber. Há palavras que permitem dessas ambiguidades estáveis, mais do que isso, elas vivem desta ambiguidade, delas extraem seu vigor comunicativo. Mais do que outras, tais palavras "ficam no ar", "só o tempo vai dizer". O tempo é concretizado, neste sentido, como um certo movimento da configuração de relações pessoais. Tal como o rumo da prosa, é apenas ao final que se pode "saber". Seja o final de um causo, seja o de uma pessoa, isto é, sua morte. Sorte e morte são faces da mesma moeda.

Os primos de Julia aproveitavam esse desconhecimento sobre a sorte para "atentar". Riam muito; faziam "aquela zoada" ao sugerir que o marido de Julia teria "feito coisa". O que provocava o riso, e também a irritação da moça, era a implicação amorosa desta dedução. Não riam da maldade, a moral buraqueira nunca o permitiria; quando falavam em "coisa posta" era para dizer que "até parece...", "é brincadeira". "É para atentar mode a paixão", o "bemquerer exagerado", o "ciúme besta"6. Sendo exagerado, o amor poderia ser feitiço, mas ninguém diria que era. O esposo de Julia afinal era "um homem bom", incapaz de fazer "porqueira". O amor demasiado era, enfim, o que provocava risada. O interesse da prosa era o humor do jogo de sentidos, dos deslocamentos semânticos

\footnotetext{
"A ideia de "paixão" deve ser aqui complexificada, extrapolando o sentido ligado ao amor; envolvendo também as ideias sofrimento, agressividade, furor. Esta dubiedade deve ser ressaltada. Uma ótima etnografia sobre a relação entre tal noção e as dinâmicas cotidianas e da política pode ser encontrada em Dainese (2011).
} 
possibilitados pelo acontecimento da "paixão". É como a mágica da cachaça: se passar de uma certa dose, a bebida deixa de ser "remédio" e vira "garapa do Demo". Qual a medida da dose, não se pode saber de antemão, pois ela varia infinitamente de acordo com os modos e momentos pessoais. Assim é o "sistema" buraqueiro, vive com a possibilidade nunca exterminada de algo tornar a ser o que não é. "Só o tempo é quem vai dizer", dizem eles.

\section{Sujeito indefinido: o disse-me-disse}

Nos Buracos, o "sistema do povo" reside em uma espécie de sistema de lugares, a exemplo de como FavretSaada definira o sistema de feitiçaria. Também há entre buraqueiros uma posição anunciadora na ação violenta em seu discurso da feitiçaria, e em seu discurso sobre "os outros" de um modo geral. Todavia, quem "fala", no caso dos mineiros é "o outro": "o povo é quem ficou falando"; "o povo é quem anda falando"; "os outros é que falam"; "o povo fala demais". "Povo", nestes casos, é um pronome indefinido. Os mais "chegados" da vítima repetem, O povo fala que é verdade; enquanto os "chegados" do acusado poupam-no, contra-acusando o povo acusador, É esse povo prosa ruim que anda dizendo coisa, é conversa do povo! Bestagem! Assim, a posição do terceiro termo, aquele que torna visível e significa o ato de feitiçaria, anunciando-o, é nos Buracos um pronome indefinido. Não há um annonciateur, só há controvérsia. Claro, há de haver um "prosa ruim", chamado assim por falar do assunto com menos discrição do que os outros, sugerindo uma acusação certeira, assumindo ter "visto com os próprios olhos". Mas, note, chamam-no "um prosa ruim" - o ato de acusação voltase contra o acusador. Esta distinção sobre as maneiras de comunicação de um e de outro contexto etnográfico permite-nos pensar sobre o efeito corpóreo e coletivo mais esperado pelos narradores buraqueiros: o efeito da risada, isto é, a "animação".

Nos Buracos, diversamente, as expressões de neutralização da ambiguidade, de estabilização do sentido, são menos eficazes do que no "sistema" do Bocage. Talvez a diferença entre os termos sort e "sorte" pode dizer algo sobre isto. Sort, em francês, refere-se a uma propriedade da vítima, que passa a "ter as sortes" (avoir les sorts) ou, nos casos menos graves, "uma pequena sorte" (avoir une petite sort). Assim, le sort, que poderíamos noutras ocasiões traduzir para o português a sorte, aqui não é traduzível pela expressão homônima buraqueira. No primeiro caso, trata-se da morte; no segundo, da vida. Nos Buracos, Cada pessoa "já nasce com a sua sorte". Se há a "gente ruim" que "mexe com a sorte dos outros", nisto reside um paradoxo eterno do "sistema" buraqueiro, ima ambiguidade constitutiva, não à toa expressa e criada pelo e no humor. Como se diz ali sobre o sentido daquilo que se ouve, é preciso "assuntar o rumo da prosa". Assim, o humor, rumo de todas as melhores prosas, é como um rumor, condição e efeito de um estado de ânimo, um estado de relações. Jogar com o humor é puxar o interlocutor para a brincadeira. Este deve aceita-la, ou a conversa descontrola. A brincadeira, ao mesmo tempo, também deve instigar, arriscar, jogar com a possibilidade de descontrole. Nas risadas, agressividade e ternura vivem no equilíbrio instável que permite o jogo, a "zoada", a "brincadeira". Falar da sorte costuma levar o buraqueiro aos labirintos do "cálculo". Falar dela é arriscar-se no duplo sentido, ouvi-la é também jogar com este?

Nos Buracos, os afetos são criados como efeitos de um "sistema do povo" que define a totalidade de um "pessoal"; no Bocage, o "sistema" define um circuito restrito, o das pessoas e famílias atingidas pela feitiçaria, mantendo-se em grande medida isolado do povo, les gens.

Esta diferença diz respeito à maneira como se pode relacionar o afeto (ou o descontrole) à criação contínua de "povos" e "pessoas". Como já argumentei (Carneiro, 2015-a), o humor é uma forma de impor ao ouvinte sua entrada no jogo dos sentidos, calculando os implícitos de uma verbalização que joga ela mesma com o que não diz. Creio que, como fez Favret-Saada, apropriar-se desta maneira deliberada de incluir o ouvinte (os leitores, o "povo"), nas práticas de produção de sentido, é um tática importante na escrita antropológica. Nas risadas, a agressividade e a ternura vivem no equilíbrio instável que permite o jogo, a "zoada", a "brincadeira". Falar da sorte costuma levar o buraqueiro aos labirintos do "cálculo". Falar dela é arriscar-se no duplo sentido, ouvila é também jogar com este. Assim, Julia se questionava sobre os rumos de seu casamento com uma oposição entre dois termos que na verdade escondiam um terceiro. Seria um causo de escolha ou de sorte? Ela refutava o sinal da "sorte", mas é difícil saber efetivamente o que ela refutava. Pergunto-me se a sorte à qual se negava seria o "destino dado por Deus", sentido explicitável, ou a alguma "coisa feita por gente". Não há como saber. Há palavras que permitem dessas ambiguidades estáveis, mais do que outras elas "ficam no ar", "só o tempo vai dizer".

\section{Bibliografia}

Andriolli, C. S. (2011). Sob as vestes do Sertão, o Gerais: "Mexer com criação" no Sertão do Ibama. Tese de doutorado. Campinas, SP: Unicamp.

Barbosa Neto, E. R. (2012). "O quem as coisas: feitiçaria e etnografia em Les mots, la mort, les sorts". In: Horizontes Antropológicos, Porto Alegre, ano 18, n. 37, p. 235-260, jan./jun.

Benites L. F. R. (2010). Olhando da Ribanceira: Perspectivas de Influência e Vulnerabilidade no Vale do

\footnotetext{
7 Esta ideia aproxima-se do que Huzinga (1980 [1938]) fomulou sobre o lúdico como essencial e definidor da vida humana.
} 
Alto-Médio São Francisco. Tese de Doutorado. Museu Nacional, UFRJ, Rio de Janeiro, 2010.

Besnier, N. (2009). Gossip and the everyday production of politics. Honolulu: University of Hawaii Press.

Carneiro, A. (2015a). "O sistema da mexida de cozinha". In: Comerford, Carneiro e Dainese. (orgs.). Giros etnográficos em Minas Gerais: conflito, casa, comida, prosa, festa, política e o diabo. Rio de Janeiro: 7Letras.

Carneiro, A. (2015b). O povo parente dos Buracos: sistema de prosa e mexida de cozinha. Rio de Janeiro: E-Papers.

Carneiro, A. (2014). "Um causo, um povo, uma televisão: formas análogas". In: Revista Mana vol. 20, n. 3, dez.

Carneiro, A. (2013). "Os rumos da prosa: parentes chegados, primos cunhados". In: Revista de Ciências Sociais vol. 44, n. 2. Fortaleza: UFC.

Carneiro, A. (2009). “De moça a esposa: casa, casamento e êxodo feminino no sertão mineiro". In Revista Desenvolvimento Social da Unimontes, v. 4, p. 37-45.

Carneiro, A. e Dainese, G. (2015). "Notas sobre diferenças e diferenciações etnográficas do movimento". In Revista Ruris, vol. 09, n. 1.

Comerford, J. C. (2003). Como uma família: sociabilidade, territórios de parentesco e sindicalismo rural. Rio de Janeiro : Relume Dumará.

Comerford, J; Carneiro, A. e Dainese, G. (orgs.). (2015). Giros etnográficos em Minas Gerais: conflito, casa, comida, prosa, festa, política e o diabo. Rio de Janeiro: 7Letras.

Dainese, G. (2011). Chegar ao cerrado mineiro: hospitalidade, política e paixões. Rio de Janeiro: Tese de Doutorado, PPGAS - Museu Nacional/UFRJ.

Darnton, Robert. (2010). O Diabo na Água Benta, ou a arte da calúnia e da difamação de Luis XIV a Napoleão. São Paulo: Companhia das Letras.

De Certeau, M. (1990). L'Invention du quotidien. vol.1 Arts de faire. Paris: Éditions Gallimard.

Deleuze, G. (2006 [1968]). Diferença e repetição. São Paulo: Graal.

Deleuze, G. (2000[1969]). Lógica do sentido. São Paulo: Perspectiva.
Deleuze, G. (1978). Cours de Vincennes. Disponível em: http://www.webdeleuze.com

Deleuze G. e Guattari F. (1980). Mille Plateaux. Paris: Minuit.

Favret-Saada, J. (2005 [1977]). Les mots, la mort, les sorts. Paris: Galimard.

Favret-Saada, J. (1990). "Être affecté", Gradhiva. Revue d'Histoire et d'Archives de l'Anthropologie, 8: 3-9.

Goldman, M.; Viveiros De Castro, E. (2006). Abaeté, rede de antropologia simétrica. Cadernos de Campo, n. 14/15, p. 177-190. (Entrevista concedida a Aristóteles Barcelos Neto, Danilo Ramos, Maíra Santi Bühler, Renato Sztutman, Stelio Marras e Valéria Macedo).

Guedes, A. D. (2013). O trecho, as mães e os papéis: etnografia dos movimentos e durações no norte de Goiás. São Paulo: Garamond.

Huizinga, A, J. (1980 [1938]). Homo Ludens. O jogo como elemento da cultura. São Paulo, Perspectiva.

Jackson, J. (2008). Building publics, shaping public opinion: interanimating registers in Malagasy kabary oratory and political cartooning. Journal of Linguistic Anthropology 18 (2)

Medeiros, C. P. (2011). No rastro de quem anda: comparações entre o tempo do parque e o hoje em um assentamento no noroeste mineiro. Tese de Doutorado. Rio de Janeiro: UFRJ-MN/PPGAS.

Pereira, L. (2012). Os giros do sagrado: um estudo etnográfico sobre as folias em Urucuia, MG. Rio de Janeiro: 7Letras.

Weitzman, R. (2011). Entre a roça e a cidade - um processo de invenção de práticas alimentares $e$ agrícolas. Dissertação do mestrado em Antropologia Social.Programa de Pós-Graduação em Antropologia Social, Museu Nacional, UFRJ, Rio de Janeiro.

Palmeira, M. e Almeida, A.W. (1977). "A invenção da migração". In Projeto Emprego e Mudança SócioEconômica no Nordeste - Relatório de Pesquisa. Rio de Janeiro: Museu Nacional.

Zourrabichvili, F. (2004). O Vocabulário de Deleuze. Rio de Janeiro: Relume-Dumará. 